\title{
CINDERELLA PÓS MODERNA: UM ESTUDO COMPARATIVO ENTRE O CONTO DOS IRMÃOS GRIMM E A ADAPTAÇÃO CINEMATOGRÁFICA $A$ CINDERELLA STORY
}

\author{
Bianca Grela (UEM) \\ Camila Heloise Paes (UEM) \\ Maria Heloisa Teixeira da Silva (UEM) \\ Orientadora: Josimayre Novelli Coradim (UEM)
}

\section{RESUMO}

A presente pesquisa, de caráter interpretativista, tem como objetivo apresentar uma análise comparativa entre o conto Cinderella (1812), dos Irmãos Grimm, e a adaptação cinematográfica $A$ Cinderella Story (2004), no que se refere às possíveis alterações no tempo, espaço, personagens principais e enredo. A análise dessa investigação foi pautada nas teorias da literatura maravilhosa e adaptação cinematográfica, tendo como teóricos Del Grosso (2012), Todorov (1975) e Theodoro (2012). Além disso, propôs-se informar sobre a evolução existente na literatura e na cinematografia ao longo do tempo, principalmente naquelas categorias. Como resultado, de modo geral, foi possível compreender as adaptações feitas entre o conto e o filme no que diz respeito aos operadores narrativos citados. Além disso, observou-se que, para aproximar-se do público da época em que o filme foi lançado, o seu produtor optou pelo uso de recursos comuns a esse público, daí a necessidade de serem feitas tais adaptações. É importante ressaltar, ainda, que este estudo justifica-se pela contribuição à área de pesquisa sobre adaptações de contos maravilhosos tradicionais às telas, seguindo a tendência contemporânea voltada ao tema.

Palavras-chave: Adaptação cinematográfica; Conto maravilhoso; Cinderella.

\section{INTRODUÇÃO}

Nesta pesquisa, de caráter interpretativista, faremos uma análise comparativa no que se refere às possíveis alterações em quatro operadores narrativos: tempo, espaço, personagens principais e enredo entre o conto maravilhoso Cinderella (1812), dos Irmãos Grimm, e o filme A Cinderella Story (2004), produzido pelo estúdio Warner Bros, que é uma adaptação para o público jovem da época em que foi lançado. Diversos elementos do conto foram modificados para que ocorresse certa aproximação com o público, já que a versão do conto em análise foi registrada em 1812. Optamos pelo conto Cinderella por ser bastante conhecido, objetivando, assim, certa proximidade com o público leitor. Além disso, este estudo justifica-se pela contribuição à área de pesquisa sobre adaptações de livros, especificamente de contos maravilhosos tradicionais às telas, seguindo a tendência contemporânea voltada ao tema.

Atualmente, as adaptações de contos de fadas tomam conta dos universos infantil e adolescente, principalmente por meio de produções cinematográficas. A versão de Cinderella utilizada neste trabalho é uma das primeiras que apresentam 


\section{SEMINÁRIO DE PESQUISA EM CIÊNCIAS HUMANAS - SEPECH \\ Humanidades, Estado e desafios didático-científicos \\ Londrina, 27 a 29 de julho de 2016}

acontecimentos que podem - ou não - serem explicados, já que o mundo em que a história faz parte permite que isso aconteça.

O conto narra, basicamente, a história de uma jovem, Cinderela, que perdeu a mãe e logo passou a morar com o pai, a madrasta e duas filhas. As meio-irmãs tiraram de Cinderela suas roupas, sapatos e fizeram-na trabalhar como escrava em sua própria casa. O príncipe da região resolveu dar uma festa de três noites para encontrar a noiva ideal, e as meio-irmãs de Cinderela foram. A moça queria muito ir, porém não permitiram e, além disso, ela não possuía trajes adequados. Então, Cinderela foi ao túmulo de sua mãe e pediu aos pássaros para que lhe trouxessem um vestido adequado para o baile. O pedido foi realizado e ela foi ao baile sem ser reconhecida pelas suas meio-irmãs. Assim foram as três noites de festa, os pássaros levaram a ela três lindos vestidos diferentes. Nas três noites, ela era a mais bonita da festa e o príncipe dançou só com ela. $\mathrm{Na}$ hora de ir embora, ela saía correndo e o príncipe não a encontrava. $\mathrm{Na}$ última noite, ao sair correndo da festa, acabou perdendo um pé de seu sapato, e o príncipe o guardou para que, posteriormente, pudesse encontrá-la. O príncipe começou a busca pelo reino e, após ser enganado pelas duas meio-irmãs de Cinderela, finalmente a encontrou e eles se casaram. Como punição, as duas irmãs ficaram cegas.

Já o filme, A Cinderella Story, produzido pelo estúdio Warner Bros e lançado em 2004, apresenta a história de Sam Montgomery, uma estudante do Ensino Médio que mora com sua madrasta Fiona e com duas meio-irmãs, que a tratam muito mal e obrigam-na a trabalhar na lanchonete que era de seu pai. Certo dia, Sam conhece, pela internet, um admirador secreto com o pseudônimo de "Nômade". Os dois se correspondem por algum tempo e marcam um encontro num baile que ocorrerá em breve no colégio. O romance secreto é levado adiante com a ajuda dos amigos de Sam, Rhonda e Carter. Conforme o website Cineplayers (2004), no dia do baile, Sam fantasiada de Cinderela mascarada - e Nômade se conhecem. Ela percebe, então, que ele é Austin, um colega do colégio. Após o encontro, Sam vai embora, esquecendo acidentalmente seu celular. Austin começa, então, uma busca pela verdadeira identidade da Cinderela mascarada. No final do filme, Sam fica com Austin, consegue recuperar o que era de seu pai e sua madrasta se torna sua empregada.

Após essa breve contextualização das histórias narradas no conto e no filme, reiteramos que este estudo apresentará uma análise comparativa entre conto e filme no que se refere aos quatro elementos da narrativa já mencionados e objetiva a obtenção de conclusões a respeito das possíveis adaptações, suas evoluções e necessidade de serem feitas. $\mathrm{O}$ artigo encontra-se estruturado da seguinte maneira: referencial teórico; análise e discussão dos resultados (tempo, espaço, personagens principais e enredo) e considerações finais.

\section{REFERENCIAL TEÓRICO}

Para desenvolver a análise comparativa serão usadas teorias de duas frentes: literatura maravilhosa e adaptação cinematográfica.Os contos orais da idade média originaram a literatura fantástica. De acordo com Todorov (1975), esses contos são obras que fazem um pacto com os leitores desde o início da leitura, apresentando mundos em que podem existir aspectos estranhos e sobrenaturais, com textos e personagens que causam estranhamento perante o que é real. 


\section{SEMINÁRIO DE PESQUISA EM CIÊNCIAS HUMANAS - SEPECH \\ Humanidades, Estado e desafios didático-científicos \\ Londrina, 27 a 29 de julho de 2016}

O universo do maravilhoso está naturalmente povoado de dragões, de unicórnios e fadas; os milagres e as metamorfoses ali são contínuos; a varinha mágica é de uso corrente; os talismãs, os gênios, os elfos e os animais agradecidos abundam; as madrinhas satisfazem em um segundo os desejos das órfãs merecedoras de ajuda. (CAILLOIS, 1966, p.11).

É possível encontrar registros que postulam que os irmãos Jacob e Wihelm Grimm foram um dos primeiros a adaptarem histórias desse tipo, que são reconhecidas mundialmente até os dias atuais (FRANZIN, 2012). De acordo com Barthes (1987 apud NAREMORE, 2000), adaptar é uma maneira de analisar e interpretar a obra, e não desvalorizar o texto original. Assim, é possível criar diferentes visões de uma mesma obra.

Conforme o passar do tempo e o contexto social de cada época, é plausível afirmar que diversos contos passaram por adaptações. O conto Cinderella, versão dos Irmãos Grimm (1812), apresenta os traços da mulher da época, em que a sociedade a domesticava e mostrava um pensamento burguês e que a mulher esperava um "bom" casamento para ascender socialmente. Já a adaptação cinematográfica $A$ Cinderella Story (2004), foco de análise desta pesquisa, apresenta as características de grande parte das mulheres do século XXI, que além de trabalhos domésticos, se preocupam também com suas vidas profissional.

Segundo Theodoro (2012, p. 16),

O exemplo das diferentes versões de Cinderella mostra como os cerne das histórias era preservado, ou seja, o enredo e o significado moralizante inserido no conto estão presentes em todas as versões, independente da época ou do local em que a versão foi produzida. [...] Os detalhes podem mudar, mas aquilo que caracteriza a essência da narrativa continua o mesmo.

Isso também acontece nas adaptações cinematográficas, que, no século $\mathrm{XX}$, se apropriaram dos contos de fada e difundiram-nos pelo mundo. Essa ligação entre cinema e literatura acontece porque ambas têm sua raiz na narrativa, contendo, nos dois, elementos como tempo, espaço, personagens e enredo, aspectos essenciais para essas manifestações artísticas, além do que é chamado, por Franco Junior (2009), de movimento próprio do gênero, introdução, desenvolvimento e conclusão, que são articulados em torno do conceito de conflito dramático, encontrados tanto no conto quando na adaptação unidos da origem narrativa.

De acordo com Metz (1972, p.61), o cinema e a literatura se constituem da mesma forma, pela narrativa.

A fórmula básica, que nunca foi alterada, é aquela que consiste em chamar de "filme" uma grande unidade que nos conta uma estória e "ir ao cinema" é ir assistir a toda estória. [...] Era necessário que o cinema fosse bom contador, que ele tivesse a narratividade no corpo, para que as coisas tenham alcançado e tenham permanecido desde então no ponto em que as encontramos hoje. 


\section{SEMINÁRIO DE PESQUISA EM CIÊNCIAS HUMANAS - SEPECH \\ Humanidades, Estado e desafios didático-científicos \\ Londrina, 27 a 29 de julho de 2016}

A adaptação, que, conforme Stam (2006, p. 24), é considerada um gênero "subliterário" e "parasitário", também faz parte da "literaridade". Além disso, está sendo inserido na reformulação da própria categoria, ou seja, é igualmente importante para o discurso e a prática não literária, produzindo, assim, uma visão mais tolerante frente a esta prática.

Com este apanhado teórico, pode-se observar que adaptação cinematográfica e literatura são manifestações artísticas próximas não somente por sua base narrativa, mas também por se completarem em outros aspectos, baseando-se, principalmente, no contexto histórico. Pensamos que uma adaptação não deve ser vista como a desvalorização de uma obra literária.

\section{ANÁLISE E DISCUSSÃO DOS RESULTADOS}

Nesta seção, serão apresentadas, analisadas e comentadas as possíveis adaptações feitas do conto para o filme no âmbito dos elementos da narrativa, tempo, espaço, personagens principais e enredo.

\subsection{O tempo em Cinderella e em $A$ Cinderella Story}

Ao comparar o tempo do filme A Cinderella Story (2004) com o do conto de Jacob e Wihelm Grimm (1812), a primeira coisa que notamos e já diferenciamos um do outro é a tão famosa frase de início "Era uma vez", que, de acordo com Bergson (1979, apud Del Grosso, 2012, p. 25), é "um tempo poético aquele que faz durar o tempo vivido, denominado de duração da consciência". O tempo é criado pelo imaginário, ou seja, "através de um tempo passado, um mundo de ficção é criado no imaginário, onde é possível viajar no tempo" (DEL GROSSO, 2012, p. 26). Essa expressão, presente apenas no filme, remete a um clima mágico. Apesar de não apresentar nenhum elemento mágico na trama, há esse contraste, a impressão de o tempo estar suspenso, que leva o leitor a um retorno da memória, uma corrente fluida, continua e ininterrupta.

No filme, o tempo nos conduz a uma nova era, a modernidade: diferente do conto, sem passarinhos que realizam desejos, mas com pessoas que lutam para conseguir realizar seus sonhos. Mesmo sem a presença de elementos mágicos, ao chegar meia noite, há um desencanto do imaginário: seu vestido de princesa, sua noite de folga, o carro que acaba "esmagado" pela placa da lanchonete, tudo isso se compromete. Então, há a volta no tempo, quando Sam volta a ser uma garota ordinária do colégio que trabalha na lanchonete. O mesmo acontece no conto, quando chega a manhã - no caso, não é meia noite - Cinderela volta a trabalhar, volta ao tempo de escravidão, das cinzas.

Segundo Franco Junior (2009), é possível dividir o tempo em categorias: o tempo cronológico, que é definido pela sucessão cronológica dos acontecimentos que são narrados; o tempo histórico, que diz respeito à época ou momento histórico, contexto social em que a história se desenvolve; o tempo psicológico, um tempo subjetivo, vivido ou sentido pela personagem, que se desenvolve em acordo com o seu estado de espírito; e o tempo do discurso, que se trata da elaboração do tempo da

\footnotetext{
1 "Once upon a time” (tradução nossa)
} 


\section{SEMINÁRIO DE PESQUISA EM CIÊNCIAS HUMANAS - SEPECH \\ Humanidades, Estado e desafios didático-científicos \\ Londrina, 27 a 29 de julho de 2016}

história pelo narrador; que pode ser por ordem linear, por alteração da ordem temporal (analepse ou prolepse), ou por ritmo dos acontecimentos.

O tempo da história (ou cronológico) do conto é simples, assim como o tempo do discurso. A história começa com a mãe de Cinderela doente, que logo falece, deixando a moça com o pai. Triste, a menina ia ao túmulo da mãe todos os dias, então a primavera chega levando a neve embora e trazendo junto dela outra esposa para seu pai e, com essa esposa, trabalho a ser feito dia e noite. Um dia, Cinderela planta uma muda que ganhou do pai, e posteriormente se transformaria numa bela árvore, no túmulo de sua mãe e vai três vezes ao dia visita-la. O rei anuncia um festival de três dias para o príncipe encontrar uma noiva, e Cinderela vai à festa escondida. Na manhã seguinte ao baile, o príncipe vai atrás da moça que perdeu um sapatinho e que dançou com ele todos os dias. Depois de ser enganado duas vezes pela madrasta, ele finalmente encontra Cinderela, levando-a embora para se casarem. É narrado por ordem linear e por ritmo dos acontecimentos, não há analepses ou prolepses.

O filme segue quase o mesmo estilo do conto. Inicia-se com a personagem Sam pequena, vivendo com o pai, feliz. Então, o pai se casa novamente e, um tempo depois, morre num terremoto, deixando a filha com a madrasta. $O$ filme sofre um avanço de oito anos, quando Sam ainda vive com a madrasta e as meio-irmãs e trabalha para elas, em casa e na lanchonete. O filme também marca a questão temporal através da seca que assola a cidade em que se desenrola a trama. Depois dos oito anos passados, a história se desenrola em cinco dias. No primeiro dia, é feita a apresentação de toda a rotina dos personagens, em especial da Sam - Cinderella -, e de Austin, no caso o príncipe. Todo esse dia é marcado por marcas temporais, como:

"Where have you been?"; "We haven't talked in ages?"; "We talked this morning."

No segundo dia à noite, é o baile do colégio que, diferente do conto, acontece em apenas um dia e não três. Sam e Austin combinaram de se encontrar na festa e, como no conto, a madrasta não a deixa ir e a manda trabalhar na lanchonete em sua noite de folga. Após ser convencida por seus amigos, Sam decide ir ao baile escondida e voltar até a meia noite, que é o horário que sua madrasta volta. Quando chega ao baile, às $23 \mathrm{~h}$ ela encontra Austin, e os dois vão passear no jardim, conversar e dançar. Quando o celular de Sam, programado para despertar às $00 \mathrm{~h}$, apita, a garota sai correndo para voltar à lanchonete, sem se identificar. O terceiro dia é marcado pela procura de Austin pela "Cinderella", contudo, é somente quarto dia da história que a identidade de Sam é descoberta.

Por fim, no quinto dia é que tudo se desenrola. Sam se demite da lanchonete e sai da casa da madrasta e vai ao jogo do time de Austin para conversar com ele e esclarecer tudo. Depois de se acertarem e do beijo do casal, começa a chover, pondo fim à seca do começo do filme. A partir de então, aparecem diversas cenas: Sam achando o testamento do pai dela, em que ele deixa tudo para sua filha; a madrasta e as meio-irmãs sofrendo e ela e Austin indo para a universidade juntos. $\mathrm{O}$ tempo histórico do filme se diferencia do conto, o momento histórico, o contexto social em que as histórias se desenvolvem são diferentes, porém a estrutura, o tempo cronológico e de discurso são extremamente semelhantes. 


\section{SEMINÁRIO DE PESQUISA EM CIÊNCIAS HUMANAS - SEPECH \\ Humanidades, Estado e desafios didático-científicos \\ Londrina, 27 a 29 de julho de 2016}

\subsection{O espaço em Cinderella e em $A$ Cinderella Story}

A história de Cinderella tem três espaços principais: primeiramente, se passa no espaço da casa da moça, em que ela vive com seu pai e, posteriormente, com a madrasta e as meio-irmãs. Ainda, acontece no túmulo da mãe de Cinderela, onde a moça faz constantes visitas. Por último, o espaço do castelo do príncipe, em que é realizado o baile.

O filme tem apenas um espaço em comum com o conto: a casa em que Sam vive com o pai, a madrasta e as meio-irmãs. Na adaptação cinematográfica, existe uma lanchonete, que era do pai de Sam e a menina trabalha lá para conseguir seu sustento. É onde ela se encontra com seus amigos e obtém força para correr atrás de seus sonhos, então, pode ser considerado um espaço principal. Por fim, o colégio. Grande parte da história se passa lá, é onde Sam tem "encontros virtuais" com Austin, onde ocorre o baile e onde, no final, o casal principal se entende.

Conforme Barthes (1987, apud NAREMORE, 2000), a adaptação de espaço, do castelo para o colégio e a lanchonete, não tem o objetivo de desvalorizar o texto original, e sim de se aproximar do público da época em que foi lançado. Além disso, visa proporcionar ao espectador/leitor uma nova versão do conto, que pode resultar em diferentes interpretações e análises, todavia, sem alterar o que "caracteriza a essência da narrativa" (THEODORO, 2012, p. 16).

\subsection{Personagens principais em Cinderella e em $A$ Cinderella Story}

No conto Cinderella, os principais personagens são Cinderela, protagonista; a madrasta, antagonista; as meio-irmãs e o príncipe. Em A Cinderella Story, Sam; Fionna, a madrasta; Austin e as meio-irmãs, Brianna e Gabriella, são os personagens principais. Diferentemente do conto, no filme, Sam tem dois amigos: Carter, que a ajuda a revelarse para Austin, e Rhonda, funcionária da mesma lanchonete que Sam. É Rhonda quem dá a Sam um vestido para ir ao baile. Além disso, há a personagem Shelby, exnamorada de Austin que faz de tudo para que o romance dos dois não dê certo.

A personagem Cinderela, do conto, e Sam, do filme, se distinguem na personalidade, já que Sam é determinada em correr atrás do que quer e enfrenta sua madrasta, tem seus sonhos e anseios e faz o que pode para realizá-los, enquanto Cinderela é uma garota que sofre e chora no túmulo da mãe. As personalidades das duas personagens se assemelham ao saírem escondidas para o baile, adquirindo certa autonomia em ambas as histórias. As madrastas têm o mesmo perfil: cruéis, que priorizam as filhas e repreendem a enteada. Ademais, o príncipe e Austin também têm características parecidas, são determinados em encontrarem a mulher que amam.

Além disso, constatamos que, no conto, as meio-irmãs tem um caráter um tanto quanto perverso, em maltratar Cinderela e chegarem ao ponto de danificarem seus pés. $\mathrm{Na}$ adaptação cinematográfica, tendem mais para o lado cômico, cometendo atitudes absurdas - entretanto, não perversas - para atrapalharem a vida de Sam. Além do mais, Rhonda e Carter se mostram verdadeiros amigos de Sam e pessoas em que ela pode confiar. Eles a apoiam e a encorajam em suas decisões. Por último, a personagem Shelby, que possui caráter duvidoso e comete pequenos delitos para atrapalhar o romance principal, entre Sam e Austin. 


\section{SEMINÁRIO DE PESQUISA EM CIÊNCIAS HUMANAS - SEPECH \\ Humanidades, Estado e desafios didático-científicos \\ Londrina, 27 a 29 de julho de 2016}

Consideramos importante, principalmente, a adaptação feita do conto para o filme na personalidade das meio-irmãs de Cinderela/Sam. Acreditamos que fugiria do objetivo principal do filme, uma comédia romântica adolescente, se Brianna e Gabriella continuassem perversas e cometendo atrocidades para conquistar Austin, então, foi necessária uma adaptação, em que elas se tornaram personagens leves e engraçadas, sem perderem sua característica principal, o caráter duvidoso.

\subsection{Enredo em Cinderella e em $A$ Cinderella Story}

Cinderella é classificado como conto maravilhoso devido a seus acontecimentos mágicos e sobrenaturais. As ações, organizadas em situação inicial, quebra da situação inicial, conflito, clímax e desfecho, constroem o enredo. É possível notar algumas diferenças entre o enredo da adaptação cinematográfica e do conto, por exemplo, o narrador, que, no conto é, heterodiegético - "é aquele que não é coreferencial com nenhuma das personagens da diegese, [...] não participa, por conseguinte, da história narrada"(FRANCO JUNIOR, 2009, p. 41) -: “A esposa de um homem rico ficou doente e, quando sentiu que seu fim estava próximo, chamou sua única filha para sua cama e disse $[\ldots]^{2}$, e, no filme, autodiegético, que, conforme Franco Junior (2009, p. 41), é aquele que narra sua própria história, ou seja, a história é apresentada pela personagem Sam. Contudo, o enredo "base" é mantido.

Cinderela pode ser considerada um dos arquétipos mais relevantes da literatura. As diversas versões fazem com que a cada vez mais amplie esse imaginário, com novos elementos e construindo uma literariedade a partir das pluralidades de sentidos e símbolos. As versões servem para renovar a sua linguagem verbal ou não verbal da história de um amor com final feliz, com elementos novos, alterando alguns pontos temáticos dos personagens, mas nunca a essência da sua história. (DEL GROSSO, 2012, p. 23).

A situação inicial, tanto do conto como do filme, retrata Cinderela/Sam com seu pai. A quebra da situação inicial, da harmonia, se inicia quando o pai da Cinderela/Sam se casa novamente, dando à menina uma madrasta e duas meio-irmãs invejosas e continua com o surgimento do baile. Dando início ao conflito, Cinderela/Sam não têm permissão de ir ao baile. O conflito vai até o momento em que a menina dança no baile e, logo depois, perde o sapatinho/celular. Neste ponto, é iniciado o clímax - ponto alto da história -: Cinderela/Sam vai embora e o príncipe/Austin não sabe quem é a moça. Aí, tem-se a "saga" para descobrir a identidade da menina misteriosa. O desfecho acontece com o descobrimento da identidade da moça e o casal feliz junto em ambas as obras.

Todavia, podem-se notar os elementos e ações diferentes no conto e no filme. Além de serem escritos em épocas diferentes, têm finalidades distintas. O conto foi escrito como uma narrativa moralizante, para educar os leitores, o que pode ser percebido na fala da mãe e do narrador ao final do conto, que retoma as características

\footnotetext{
2 "A rich man's wife became sick, and when she felt that her end was drawing near, she called her only daughter to her bedside and said [...]" (GRIMM, 1812, linha 1) - tradução nossa.
} 


\section{SEMINÁRIO DE PESQUISA EM CIÊNCIAS HUMANAS - SEPECH \\ Humanidades, Estado e desafios didático-científicos \\ Londrina, 27 a 29 de julho de 2016}

"piedosa e bondosa", , além da forma como a personagem se comporta dentro de toda a história, em que mesmo com toda humilhação das irmãs e da madrasta, sempre se mostra boa e piedosa.

Na obra cinematográfica, Sam, a Cinderela, na época de lançamento, 2004, fez muito sucesso com público jovem. O filme não foi escrito como uma obra moralizante, pelo contexto histórico e social, é uma obra romântica, direcionada ao entretenimento do público jovem, com uma história que já conhecem desde criança com elementos não mágicos: a garota órfã trabalha de garçonete em uma lanchonete para conseguir seu próprio dinheiro para pagar a faculdade. Não é o mesmo perfil da personagem submissa do conto dos Grimm, que em nenhum momento do conto enfrenta a madrasta diretamente, enquanto no filme há esse momento, em que Sam enfrenta sua madrasta Fionna para conseguir o que deseja.

Consideramos interessante postular que o pai de Cinderela, no conto, permanece vivo em toda a história e, mesmo assim, a madrasta é perversa com a enteada, o homem não a defende em momento algum, é indiferente. Já no filme, somente após a morte do pai a madrasta passa humilhar Sam, porém, é possível percebemos logo nas primeiras cenas do filme que a nova mulher não gosta da garota. Ao fazerem a foto da nova família, Fionna deixa buquê cair para que Sam o pegue e não apareça na foto. Assim, mostra ao público a antipatia da madrasta pela garota.

Os elementos mágicos de Cinderella estão sempre ligados aos acontecimentos para ajudar a pobre menina a realizar seus sonhos, por exemplo, são os pássaros que realizam esses desejos: "O pássaro trouxe um vestido prata e dourado para ela, e sapatos bordados de seda prata"4. Em A Cinderella Story, não há elementos mágicos, são os amigos que ajudam e incentivam Sam a realizar seus próprios desejos. Contudo, em uma das cenas, o espectador se depara com o estranho, entretanto não chega ao maravilhoso nem ao fantástico (Todorov, 1975) presentes no conto: quando Sam está com medo de ir à festa porque Fionna não permite e deixa muitas tarefas domésticas para a garota fazer até a $00 \mathrm{~h}$, seus amigos insistem e uma guitarra rasga o papel de parede da lanchonete, que revela a frase que seu pai sempre dizia para

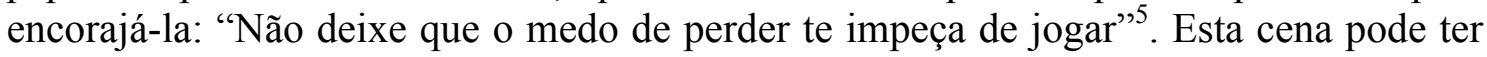
uma explicação cientifica pela lei gravidade, com sua força de atração de objetos, mas também pode ser interpretado com algo sobrenatural ao considerar o momento em que a personagem precisava do apoio do pai, ele "veio" para lhe mandar uma mensagem.

Conforme Eco (1994, p. 9),

Qualquer narrativa de ficção é necessária e fatalmente rápida porque, ao construir um mundo que inclui uma multiplicidade de acontecimentos e de personagens, não pode dizer tudo sobre esse mundo. Alude a ele e pede ao leitor que preencha toda uma série de lacunas. Afinal (como já escrevi), todo texto é uma máquina preguiçosa pedindo ao leitor que faça uma parte do seu trabalho. Que

\footnotetext{
3 "pious and good" (GRIMM, 1812, linha 1) - tradução nossa.

4 "Then the bird threw a gold and silver dress down to her, and slippers embroidered with silk and silver" (GRIMM, 1812, linha 49) - tradução nossa.

5 "Never let the fear of striking out keep you from playing the game" (A Cinderella Story, 2004) tradução nossa.
} 


\section{SEMINÁRIO DE PESQUISA EM CIÊNCIAS HUMANAS - SEPECH \\ Humanidades, Estado e desafios didático-científicos \\ Londrina, 27 a 29 de julho de 2016}

problema seria se um texto tivesse de dizer tudo que o receptor deve compreender.

É possível perceber, tanto no filme quanto no conto, que o público/leitor tem que interpretar o que está dito, fazer inferências e cada um fará a leitura e interpretação das ações a seu modo, isso porque as duas artes têm a mesma origem, o narrar.

\section{CONSIDERAÇÕES FINAIS}

Neste estudo, o conto Cinderella, dos Irmãos Grimm (1812) e o filme $A$ Cinderella Story, produzido pela Warner Bros em 2004, apresentaram-se como um material propício para análise comparativa entre quatro categorias - tempo, espaço, personagens principais e enredo - neles presentes.

Concluímos, como resultado, que, para aproximar-se do público da época em que foi lançado, o produtor do filme optou pelo uso de recursos comuns a esse público, por exemplo, a alteração do cenário, que era um castelo, para uma escola, e a alteração do sapatinho de Cinderela, como objeto perdido, pelo celular. Reiteramos a necessidade das adaptações para que ocorra proximidade do espectador com a história, contudo, mantendo sua base original.

Este estudo contribuiu para o desenvolvimento de um olhar crítico sobre o conto e sua adaptação cinematográfica, a fim de identificar e analisar as possíveis alterações nas categorias já mencionadas, além de averiguar a necessidade de serem feitas tais adaptações. Foram compreendidas as principais adaptações feitas e de que forma se deu esse processo. Além disso, é importante ressaltar sua colaboração ao ampliar nosso conhecimento teórico e nos instigar a formular questões e ir em busca de possíveis interpretações.

\section{REFERÊNCIAS}

A CINDERELLA STORY. Estúdio Warner Bros. Direção: Mark Rosman. EUA: 2004.

BERGSON, Henri. A Evolução Criadora. Trad. de Nathanael C. Carneiro. Rio de Janeiro: Zahar, 1979. p. 40- 65.

CAILLOIS, Roger. Images, images. Paris: Corti, 1966.

DEL GROSSO, Monica Faria Rosa. O imaginário em Cinderela, Branca de Neve e A Bela $e$ a Fera. Goiânia, 2012. Disponível em: http://tede.biblioteca.ucg.br/tde_busca/arquivo.php?codArquivo=1144. Acesso em: $10 / 02 / 2016$.

ECO, Umberto. Seis passeios pelo bosque da ficção. Trad. de Hildegard Feist. São Paulo: Companhia das Letras, 1994. 


\section{SEMINÁRIO DE PESQUISA EM CIÊNCIAS HUMANAS - SEPECH \\ Humanidades, Estado e desafios didático-científicos \\ Londrina, 27 a 29 de julho de 2016}

FRANCO JUNIOR, A.. Operadores de leitura da narrativa. In: Thomas Bonnici; Lúcia Osana Zolin. (Org.). Teoria Literária - Abordagens históricas e Tendências contemporâneas. 3ed. Maringá: EDUEM, 2009, v. 1, p. 33-58.

FRANZIN, A. Quem escreveu Cinderela? Disponível em: http://www.ebc.com.br/infantil/voce-sabia/2012/10/quem-escreveu-cinderela. Acesso em: 18/04/2016.

GRIMM, Jacob and Wilhelm. Cinderella. 1812. Disponível em: http://www.pitt.edu/ dash/grimm021.html. Acesso em: 15/11/2015.

METZ, C. A significação no cinema. São Paulo: Perspectiva, 1972.

NAREMORE, J. Film adaption. New Jersey: Tutgers University Press, 2000.

Resenha A Cinderella Story. 2004. Disponível em: http://www.cineplayers.com/critica/a-nova-cinderela/312. Acesso em: 01/02/2016.

STAM, Robert. Teoria e prática da adaptação: da fidelidade à intertextualidade. Revista Ilha do Desterro A Journal of English Language, Literatures in English and Cultural Studies. Florianópolis, Brasil, 2006. Disponível em: https://periodicos.ufsc.br/index.php/desterro/article/view/2175-8026.2006n51p19/9004. Acesso em: 15/02/2016.

THEODORO, A. C. N. Era uma vez... As metamorfoses nos contos de fadas contemporâneos. Uberlândia, 2012. Disponível em: http://repositorio.ufu.br/bitstream/123456789/3562/1/EraUmaVez.pdf. Acesso em: $15 / 11 / 2015$.

TODOROV, T. Introdução à literatura fantástica. Tradução de Maria Clara Correa Castello. São Paulo: Perspectiva, 1975. 